March 2008 (vol. 9, no. 3), art. no. 0803-mds2008030001

1541-4922 @ 2008 IEEE

Published by the IEEE Computer Society

Grid Computing

\title{
A Classification of Emerging and Traditional Grid Systems
}

\author{
Heba Kurdi, Maozhen Li, and Hamed Al-Raweshidy • Brunel University
}

Emerging grids could help bridge the gap between grid technologies and users. This classification of grid systems aims to motivate research and help establish a foundation in this developing field.

he grid has evolved in numerous distinct phases. It started in the early ' 90 s as a model of metacomputing in which supercomputers share resources; subsequently, researchers added the ability to share data. This is usually referred to as the first-generation grid. By the late ' 90 s, researchers had outlined the framework for second-generation grids, characterized by their use of grid middleware systems to "glue" different grid technologies together. ${ }^{1}$ Third-generation grids originated in the early millennium when Web technology was combined with second-generation grids. As a result, the invisible grid, ${ }^{2}$ in which grid complexity is fully hidden through resource virtualization, started receiving attention. Subsequently, grid researchers identified the requirement for semantically rich knowledge grids ${ }^{2}$ in which middleware technologies are more intelligent and autonomic. Recently, the necessity for grids to support and extend the ambient intelligence vision has emerged. In AmI, humans are surrounded by computing technologies that are unobtrusively embedded in their surroundings. ${ }^{3}$

However, third-generation grids' current architecture doesn't meet the requirements of nextgeneration grids (NGG) and service-oriented knowledge utility (SOKU). ${ }^{4}$ A few years ago, a group of independent experts, arranged by the European Commission, identified these shortcomings as a way to identify potential European grid research priorities for 2010 and beyond. The experts envision grid systems' information, knowledge, and processing capabilities as a set of utility services. ${ }^{3}$

Consequently, new grid systems are emerging to materialize these visions. Here, we review emerging grids and classify them to motivate further research and help establish a solid foundation in this rapidly evolving area.

\section{Emerging grids}

The fundamental gap between grid technologies and the prospective NGG vision places pervasiveness and the ability to self-manage as the top two grid research priorities. ${ }^{5}$ Pervasiveness is a composite feature that involves other primitive features, mainly accessibility, user-centricity, and dynamic interaction. Here, we survey emerging grids and classify them on the basis of four design featuresaccessibility, user-centricity, interactivity, and manageability-which are accountable for the materialization of the NGG vision. We give a broad view of the amount and type of work that has been done toward each feature specifically and toward the NGG vision in general, which could drive further research in this area. For simplicity, we use the term traditional grids to refer to first-, second-, and third-generation grids that lack these four design features; emerging grids refers to recent grid projects that explicitly address at least one of them.

Using these features, we can place emerging grids into four main groups: accessible grids, usercentric grids, interactive grids, and manageable grids (see table 1 ). We divide each group further into subgroups on the basis of the most apparent feature that distinguishes it from traditional grids. Table 1 also gives examples of projects in each category. This study's main concern is to classify grid systems rather than to survey all available grid projects. Therefore, the example projects aren't exhaustive but are comprehensive enough, however, to cover all the features of the emerging grid 
they represent. We've narrowed each grid's scope to concentrate on one feature per category. This is why we haven't used names such as ubiquitous or pervasive grids; they imply supporting combinations of features such as accessibility, interactivity, and user-centricity.

Table 1. A Classification of Emerging Grids.

\begin{tabular}{|c|c|c|c|c|}
\hline $\begin{array}{l}\text { Design } \\
\text { features }\end{array}$ & $\begin{array}{l}\text { Emerging } \\
\text { grids } \\
\text { categories }\end{array}$ & $\begin{array}{l}\text { Emerging grids } \\
\text { subcategories }\end{array}$ & $\begin{array}{l}\text { Main } \\
\text { difference } \\
\text { from } \\
\text { traditional } \\
\text { grids }\end{array}$ & Example projects \\
\hline \multirow[t]{3}{*}{ Accessibility } & $\begin{array}{l}\text { Accessible } \\
\text { grids }\end{array}$ & Ad hoc grids & $\begin{array}{l}\text { Have no } \\
\text { predefined } \\
\text { entry points }\end{array}$ & $\begin{array}{l}\text { OurGrid (www.ourgrid.org) and } \\
\text { myGrid (www.mygrid.org.uk) }\end{array}$ \\
\hline & & Mobile grids & $\begin{array}{l}\text { Support } \\
\text { mobility of } \\
\text { clients, } \\
\text { services, or } \\
\text { both }\end{array}$ & $\begin{array}{l}\text { Akogrimo (www.mobilegrids.org), } \\
\text { ISAM (Support Infrastructure for } \\
\text { Mobile Applications, } \\
\text { www.inf.ufrgs.br/ isam/English), } \\
\text { and MADAM (Mobility and } \\
\text { Adaptation Enabling Middleware, } \\
\text { www.intermedia.uio.no/display/ } \\
\text { madam/Home) }\end{array}$ \\
\hline & & Wireless grids & $\begin{array}{l}\text { Support } \\
\text { wireless } \\
\text { connections } \\
\text { between grid } \\
\text { nodes and } \\
\text { interfaces }\end{array}$ & $\begin{array}{l}\text { Home Grid and Office Grid } \\
\text { (http://wirelessgrids.net) }\end{array}$ \\
\hline \multirow[t]{2}{*}{ Interactivity } & $\begin{array}{l}\text { Interactive } \\
\text { grids }\end{array}$ & $\begin{array}{l}\text { Explicit } \\
\text { interactive grids }\end{array}$ & $\begin{array}{l}\text { Support } \\
\text { explicit real- } \\
\text { time } \\
\text { interaction } \\
\text { with end } \\
\text { users }\end{array}$ & $\begin{array}{l}\text { CrossGrid (www.crossgrid.org) } \\
\text { and edutain@grid } \\
\text { (www.edutaingrid.eu) }\end{array}$ \\
\hline & & $\begin{array}{l}\text { Context-aware } \\
\text { grids }\end{array}$ & $\begin{array}{l}\text { Interact with } \\
\text { their } \\
\text { surroundings } \\
\text { to build } \\
\text { context and } \\
\text { adapt their } \\
\text { behavior }\end{array}$ & $\begin{array}{l}\text { RUNES (Reconfigurable } \\
\text { Ubiquitous Networked Embedded } \\
\text { Systems, www.ist-runes.org), } \\
\text { SENSE (Smart Embedded } \\
\text { Network of Sensing Entities, } \\
\text { www.sense-ist.org), Hydra } \\
\text { (Networked Embedded System } \\
\text { Middleware for Heterogeneous } \\
\text { Physical Devices in a Distributed } \\
\text { Architecture, www.hydra.eu.com), } \\
\text { and MORE (Network-centric } \\
\text { Middleware for Group } \\
\text { communication and Resource }\end{array}$ \\
\hline
\end{tabular}




\begin{tabular}{|c|c|c|c|c|}
\hline & & & & $\begin{array}{l}\text { Sharing across Heterogeneous } \\
\text { Embedded Systems, www.ist- } \\
\text { more.org) }\end{array}$ \\
\hline \multirow[t]{2}{*}{ User-centricity } & $\begin{array}{l}\text { User-centric } \\
\text { grids }\end{array}$ & Personal grids & $\begin{array}{l}\text { Owned } \\
\text { and/or used } \\
\text { by } \\
\text { individuals }\end{array}$ & Personal Grid ${ }^{6}$ \\
\hline & & $\begin{array}{l}\text { Personalized } \\
\text { grids }\end{array}$ & $\begin{array}{l}\text { Implement } \\
\text { highly } \\
\text { customizable } \\
\text { grid portals }\end{array}$ & $\begin{array}{l}\text { Akogrimo (www.mobilegrids.org) } \\
\text { and MyGrid (www.mygrid.org.uk) }\end{array}$ \\
\hline \multirow[t]{3}{*}{ Manageability } & $\begin{array}{l}\text { Manageable } \\
\text { grids }\end{array}$ & Autonomic grids & $\begin{array}{l}\text { Use ideas } \\
\text { from the } \\
\text { human } \\
\text { body's } \\
\text { autonomic } \\
\text { nervous } \\
\text { system to } \\
\text { support self- } \\
\text { managing }\end{array}$ & IBM OptimalGrid $^{7}$ and AutoMAGI ${ }^{8}$ \\
\hline & & Knowledge grids & $\begin{array}{l}\text { Use } \\
\text { knowledge } \\
\text { technologies } \\
\text { to support } \\
\text { self- } \\
\text { managing }\end{array}$ & $\begin{array}{l}\text { OntoGrid } \\
\text { (www.ontogrid.net/ontogrid/index } \\
\text {.jsp), InteliGrid } \\
\text { (www.inteligrid.com), and K-Wf } \\
\text { Grid (Knowledge-Based Workflow } \\
\text { System for Grid Applications, } \\
\text { www.kwfgrid.eu) }\end{array}$ \\
\hline & & Organic grids & $\begin{array}{l}\text { Use ideas } \\
\text { from ant } \\
\text { colony to } \\
\text { support self } \\
\text { managing }\end{array}$ & Organic Grid $^{9}$ \\
\hline
\end{tabular}

\section{Categorizing grids}

In the literature, two characteristics categorize traditional grids: the type of solutions they provide and the scope or size of the underlying organization(s). We propose four additional nomenclatures to facilitate the classification of emerging grids: accessibility, interactivity, user-centricity, and manageability. We define each of these features and explain our rationale for adding them.

Figure 1 depicts our proposed classification of emerging and traditional grid systems. This classification isn't disjoint; a grid system is classified on the basis of all of these criteria. For instance, one grid might be global, voluntary, computational, mobile, interactive, personalized, and autonomic, whereas another might be project based, data oriented, restricted, for batch processing, nonpersonalized, and centralized. 


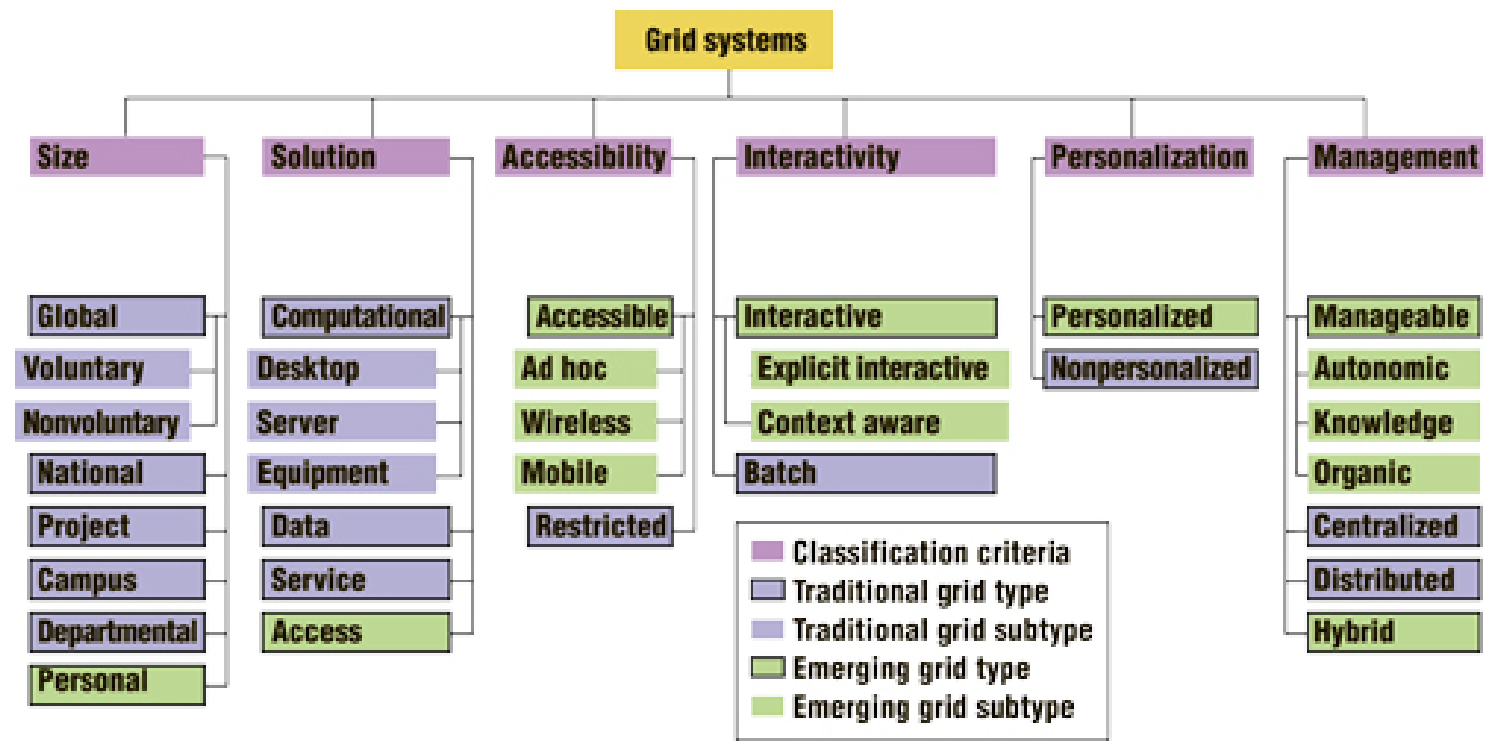

Figure 1. A classification of traditional and emerging grids.

\section{Grids classified by solution}

The main solution that computational grids offer is CPU cycles. These grids have a highly aggregated computational capacity. Depending on the hardware deployed, computational grids are further classified as desktop, server, or equipment grids. In desktop grids, scattered, idle desktop computer resources constitute a considerable amount of grid resources, whereas in server grids resources are usually limited to those available in servers. An equipment or instrument grid includes a key piece of equipment, such as a telescope. The surrounding grid-a group of electronic devices connected to the equipment-controls the equipment remotely and analyzes the resulting data. For instance, the WorldWide Telescope ${ }^{10}$ uses grid technologies to analyze and categorize data from hundreds of individual telescopes all over the world to find new phenomena.

In data grids, the main solutions are storage devices. They provide an infrastructure for accessing, storing, and synchronizing data from distributed data repositories such as digital libraries or data warehouses.

Service or utility grids provide commercial computer services such as CPU cycles and disk storage, which people in the research and enterprise domains can purchase on demand.

Access grids consist of distributed input and output devices, such as speakers, microphones, video cameras, printers, and projectors connected to a grid. These devices provide multiple access points to the grid from which clients can issue requests and receive results in large-scale distributed meetings and training sessions. ${ }^{10}$ If clients use wireless or mobile devices to access the grid, it's considered a wireless access grid or a mobile access grid.

\section{Grids classified by size}

Global grids are established over the Internet to provide individuals or organizations with grid power anywhere in the world. This is also referred to as Internet computing. Some literature further classifies global grids into voluntary and nonvoluntary grids. Voluntary grids offer an efficient solution for distributed computing. They let Internet users contribute their unused computer resources to collectively accomplish nonprofit, complex scientific computer-based tasks. Resource consumption is strictly limited to the controlling organization or application. On the other hand, nonvoluntary grids contain dedicated machines only. 
National grids are restricted to the computer resources available within a country's borders. They're available only to organizations of national importance and are usually government funded.

Project grids are also known as enterprise grids or partners grids. They're structurally similar to national grids, but rather than aggregating resources for a country, they span multiple geographical and administrative domains. They're available only to members and collaborating organizations through a special administrative authority.

Intra-grids or campus grids, in which resources are restricted to those available within a single organization, are only for the host organization's members to use.

Departmental grids are even more restricted than enterprise grids. They're only available to people within the department boundary.

Personal grids have the most limited scope of underlying organization. They're available at a personal level for the owners and other trusted users. Personal grids are still at a very early stage.

\section{Accessible grids}

In this context, accessibility means making grid resources available regardless of the access devices' physical capabilities and geographical locations. The highly structured networks of supercomputers and high-performance workstations that dominate grids today typically don't provide such accessibility. In traditional, restricted-access grids, grid nodes are stationary with a predefined wired infrastructure and entry points.

Wireless, mobile, and ad hoc grids have emerged to support grid accessibility. Accessible grids is an umbrella term that refers to these grid types (see table 1). An accessible grid consists of a group of mobile or fixed devices with wired or wireless connectivity and predefined or ad hoc infrastructures.

One of the most critical issues in understanding accessible grids is having an accurate definition, or at least determination, of each grid type (ad hoc, wireless, and mobile). Yet, researchers offer no consistent definition of any of these three terms. Ad hoc grids stress the ad hoc nature of virtual organizations, wireless grids emphasize the wireless connectivity, and mobile grids focus on mobilityrelated issues such as job migration and data replication.

An accessible grid's main characteristic is its highly dynamic nature, which results from the frequently changing structure of underlying networks and VOs due to nodes switching on and off, nodes entering and leaving, node mobility, and so on. This is why traditional service discovery, management, and security mechanisms might not be optimal for accessible grids.

Accessible grids are accessible from more geographical locations and social settings than traditional grids. This opens the door for new applications in emergency communication, disaster and battlefield management, e-learning, and e-healthcare, among other fields.

Ad hoc grids. Grids' ad hoc, sporadic nature was observed within the first documented Globus Grid application (see www.globus.org). However, traditional grids fail to support certain aspects of ad hoc environments, ${ }^{11}$ such as constantly changing membership with a lack of structured communications infrastructure. As a result, ad hoc grids have emerged.

An ad hoc grid is a spontaneous formation of cooperating heterogeneous computing nodes into a logical community without a preconfigured fixed infrastructure and with minimal administrative requirements (see figure 2 ). ${ }^{12}$ Thus, the traditional static grid infrastructure is extended to encompass dynamic additions with no requirements of formal, well-defined, or agreed-upon grid entry points. Instead, nodes can join as long as they can discover other members. ${ }^{11}$ 


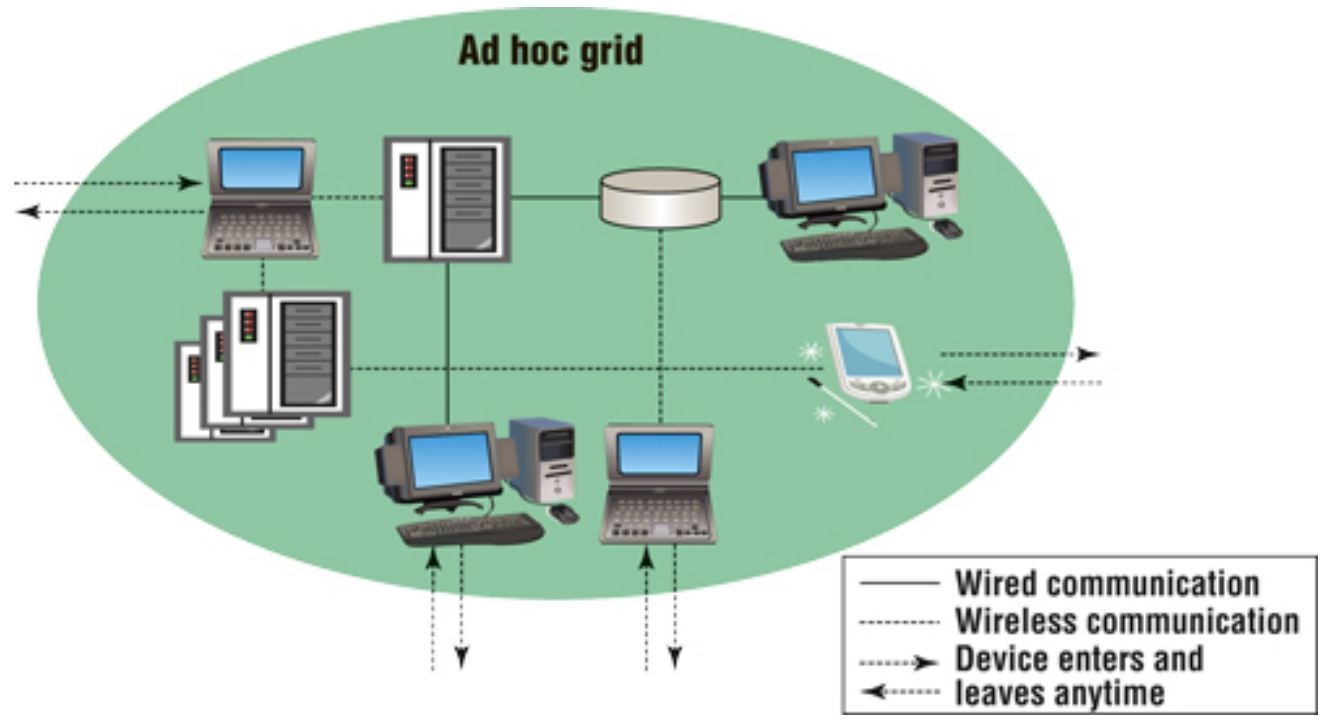

Figure 2. In an ad hoc grid, grid devices can join and leave at any time.

Some researchers strictly define ad hoc grids as grid environments without fixed infrastructures: all their components are mobile, ${ }^{13,14}$ as figure 3 shows. This grid is referred to as a mobile ad hoc grid. However, ad hoc grids focus on the grid's ad hoc nature rather than the nodes' mobility. ${ }^{11}$

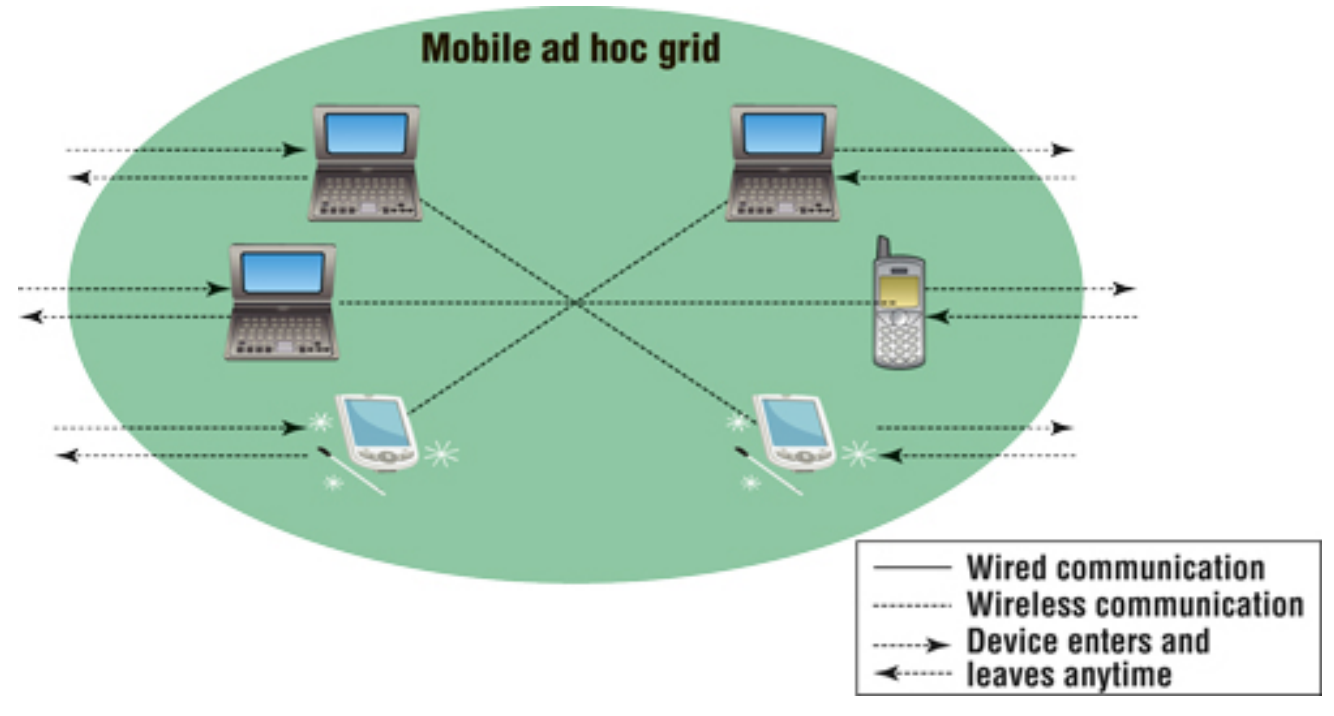

Figure 3. In a mobile ad hoc grid, all grid devices are mobile.

Ad hoc grids' main challenge is their dynamic topology, due to the rebooting of workstations and the movement or replacement of computational nodes. Technical details concerning ad hoc grid challenges and implementations are available elsewhere. ${ }^{11-14}$

Researchers have proposed varying architectures for ad hoc grids. For instance, Dan Marinescu and his colleagues introduce a virtual backbone architecture that is dynamically constructed using nodes with high resource capacity. ${ }^{13}$ Other sources ${ }^{11,12}$ suggest peer-to-peer (P2P) architectures where computing resources are equally available on demand to every peer. Existing ad hoc grid projects include OurGrid (www.ourgrid.org) and myGrid (www.mygrid.org.uk). 
Wireless grids. The wireless grid extends grid resources to wireless devices of varying sizes and capabilities such as sensors, mobile phones, laptops, special instruments, and edge devices. These devices might be statically located, mobile, or nomadic, shifting across institutional boundaries and connected to the grid via nearby devices such as desktops. ${ }^{15}$

In wireless grids, wireless devices can act as real grid nodes where part of data processing and storage is taking place, as figure 4 shows. Figure 5 illustrates the wireless access grid, a special type of wireless grid in which all wireless devices are considered pure access devices without processing or storage capabilities; ${ }^{16}$ required resources are obtained from a wired, resource-rich backbone grid.

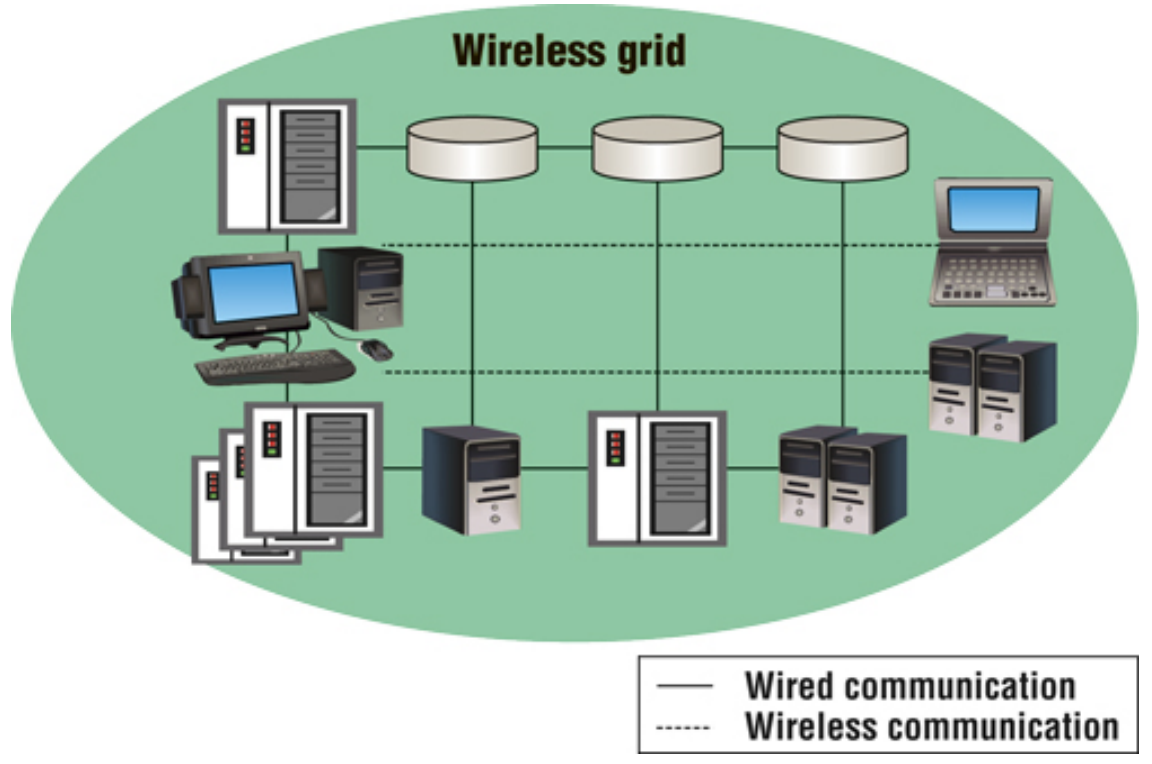

Figure 4. In a wireless grid, wireless devices participate actively in the grid as processing or storage nodes.

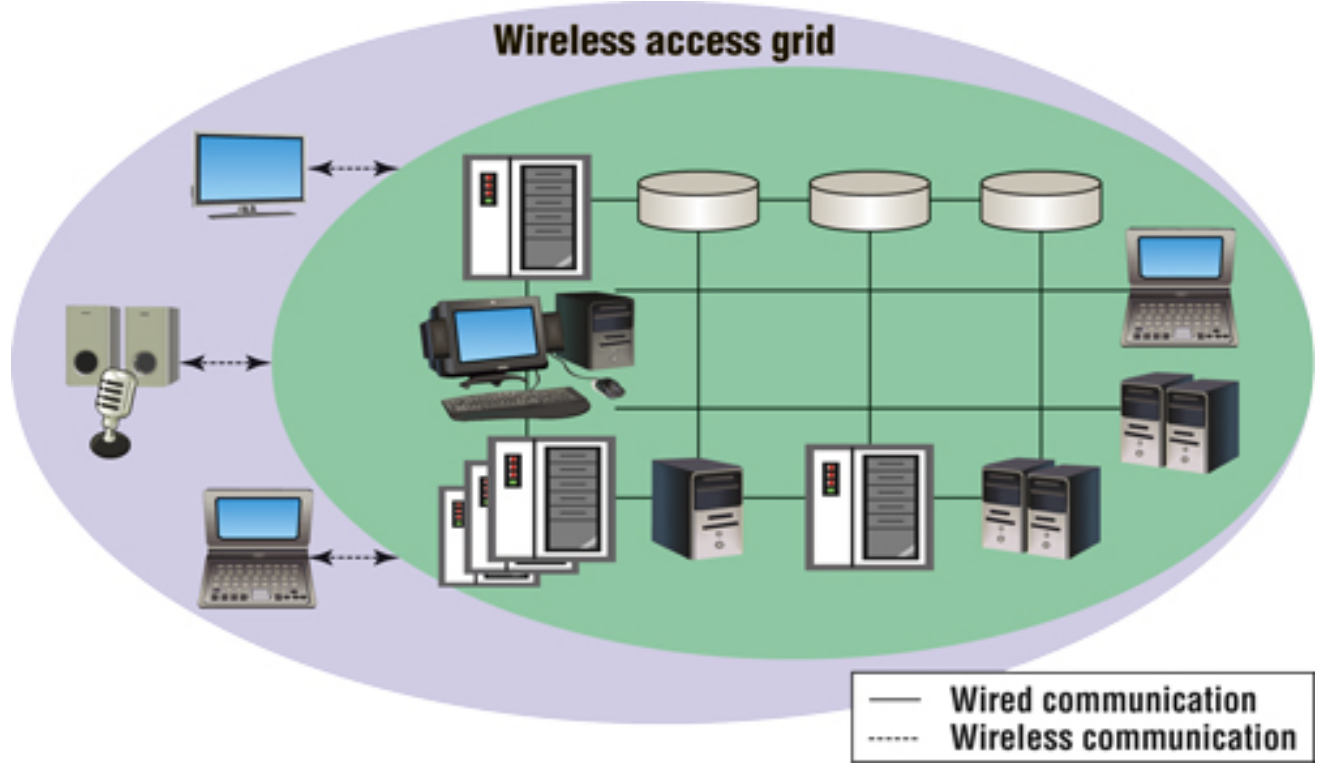

Figure 5. In a wireless access grid, wireless devices serve only as interfaces to a wired backbone grid. 
Many technical concerns arise when integrating wireless devices into a grid. These include low bandwidth and high security risks, power consumption, and latency. So, several communities, including the Interdisciplinary Wireless Grid Team (see www.wirelessgrids.net) are exploring these new issues to ensure that future grid peers can be wireless devices. ${ }^{17}$

Mobile grids. Mobile grids make grid services accessible through mobile devices such as PDAs and smart phones. Researchers usually consider these devices to be at best marginally relevant to grid computing because they're typically resource limited in terms of processing power, persistent storage, runtime heap, battery lifetime, screen size, connectivity, and bandwidth. In contrast, recent studies suggest a very different picture. ${ }^{18-24}$ The millions of mobile devices sold annually shouldn't be ignored, and some mobile devices' raw processing power is not insignificant given their mobility. ${ }^{18}$

Furthermore, in emergency situations, such as during natural disasters and on battlefields, wireless mobile devices might be the only available communication and computation services. The most important argument is that it's difficult to materialize the SOKU and AmI visions without using such devices.

As in the case of wireless devices, there are already two approaches to integrating mobile devices into grid systems. In the first approach, the grid includes at least one mobile node that actively participates by providing computational or data services ${ }^{19}$ (see figure 6 ). In the second approach, mobile devices serve as an interface to a stationary grid for sending requests and receiving results (see figure 7). Sometimes this approach is labeled mobile access to grid infrastructure, ${ }^{20}$ or simply mobile access grids.

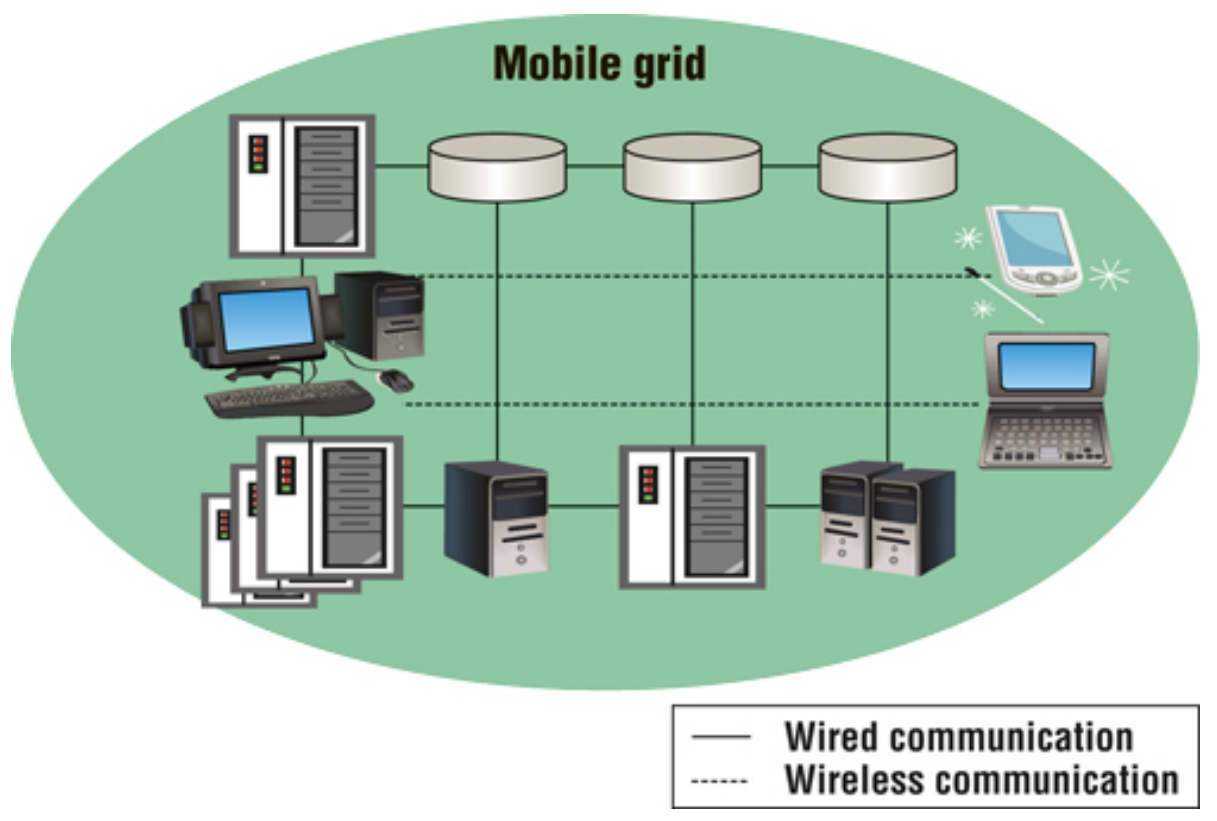

Figure 6. In a mobile grid, mobile devices participate actively in the grid as processing or storage nodes. 


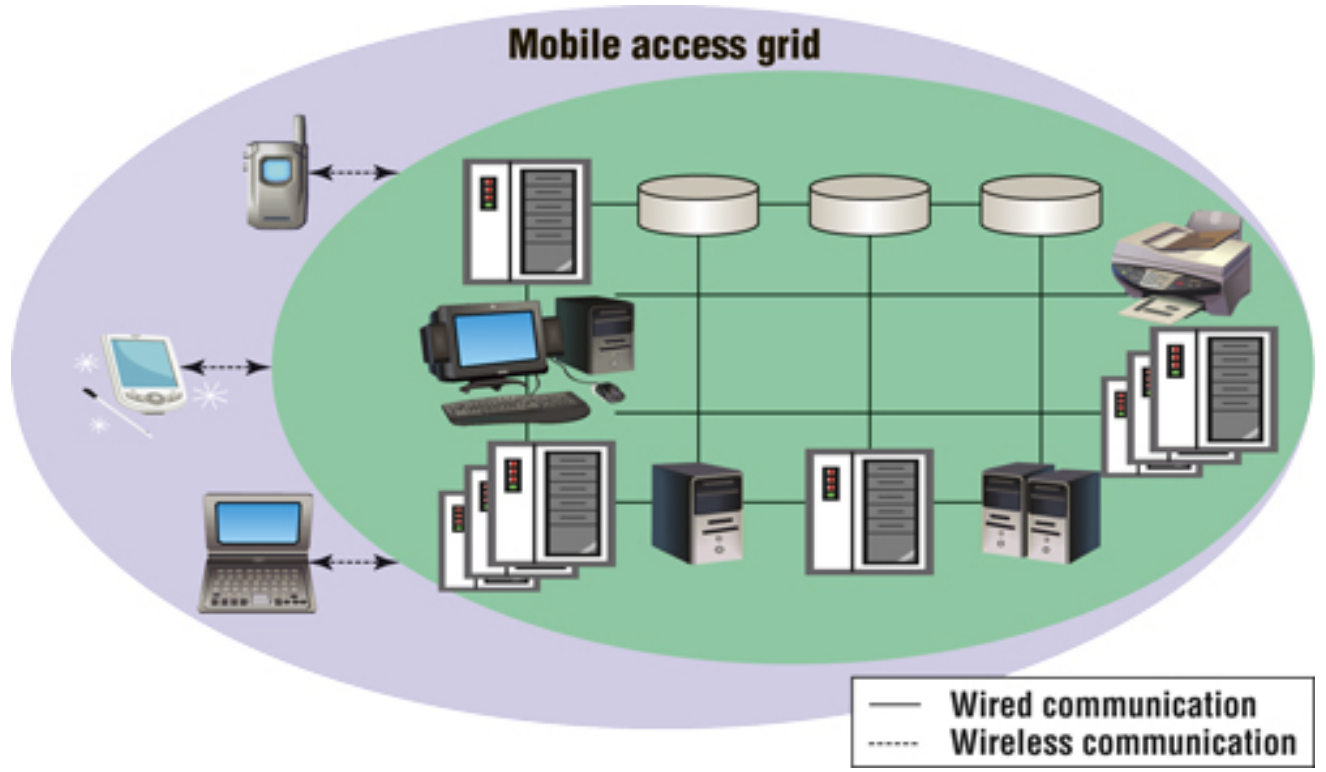

Figure 7. In a mobile access grid, mobile devices serve only as interfaces to a stationary grid.

Recently, researchers have made numerous efforts toward establishing mobile grids. You can find details concerning mobile grid requirements and challenges elsewhere. ${ }^{18-21}$ Researchers have proposed various techniques for implementing the mobile grid vision, including centralized ${ }^{19}$ and P2P structure, ${ }^{22}$ intelligent mobile agents, ${ }^{23}$ mobile grid middleware, ${ }^{24}$ and many more. Existing mobile grid projects include Akogrimo (www.mobilegrids.org) ISAM (www.inf.ufrgs.br/ isam/English), and MADAM (www.intermedia.uio.no/display/madam/Home).

\section{Interactive grids}

Some potential NGG application areas, such as real-time embedded control systems and video gaming, require rapid response times and online interactivity. The classic request/response communication paradigm of traditional grid systems (such as batch grids) can't accommodate this, ${ }^{25}$ so interactive grids are emerging to support real-time interaction.

Interactivity in grid environments can be implemented at two layers: the Web portal layer and the grid middleware layer. In the former, a Web-based grid portal is used to submit interactive jobs to a secure shell process rather than directly to the grid middleware. ScGrid portal ${ }^{26}$ falls into this category. In the latter, grid middleware is extended to support interactivity. Examples of this category include CrossGrid (www.crossgrid.org) and edutain@grid (www.edutaingrid.eu).

These examples mainly highlight explicit interactions between a grid and its users, so they're labeled explicit interactive grids. However, this is only one possible form of interaction in grid environments. Another is between a grid and its surroundings to implement a context-aware grid, which uses sensors to interactively build the context and actuators to adapt grid behaviors accordingly. The research agendas of many emerging grid projects in the areas of embedded and pervasive systems, such as RUNES (www.ist-runes.org), SENSE (www.sense-ist.org), Hydra (www.hydra.eu.com), and MORE (www.ist-more.org) emphasize context awareness.

\section{User-centric grids}

Traditional grids are designed specifically for people involved in research and large industry domains. Hence, they lack user centricity and personalization features. Consequently, it's difficult for personal 
users - that is, individuals outside these domains-to construct or use traditional grids. ${ }^{27}$ Most traditional grid systems are nonpersonalized grids.

Personalized grids are emerging grid systems with highly customizable Web portals that make them adaptable to users' needs. User centricity is a design philosophy that focuses on the needs of a system's users. Personalization is a more restrictive philosophy that aims to adapt the whole system's design to a specific user. In grid computing, user centricity could begin by displaying the user's name on a Web portal, and might end with the personalization of all information, resources, and networks underpinning grids. Research to support user centricity in grid computing is in its infancy.

We use the term user-centric grids to refer to two types of emerging grids: personalized and personal. Personalized grids have highly customizable Web portals to provide user-friendly access points to grid resources for people in different domains. For instance, the myGrid project (www.mygrid.org.uk) lets scientists establish multiple views that provide access to a user-defined subset of the registered services. These views can be specific to individual scientists or to more specialized discovery services. The Akogrimo project (www.mobilegrids.org) saves all learners' profiles and needs, such as his or her context information, and automatically loads them whenever they sign on, providing a customized, user-friendly environment for each learner. A personal grid is a personalized grid with an underlying VO of limited scope and size. It's used and/or owned by individuals. You can find a framework for a personal grid that consists of a set of networked personal desktop computers elsewhere. ${ }^{27}$

\section{Manageable grids}

A grid is highly complex and dynamic, making its management extremely challenging. ${ }^{3}$ Traditional grid-management approaches require centralized servers, extensive knowledge of the underlying systems, and a large group of experienced staff. So, grids are emerging with manageability as a main focus.

Centralized grids are traditional grid systems that use a central management scheme. In distributed grids, such as P2P grids, management is distributed.

Manageability is the capacity to manage, organize, heal, and control a system; hence, a manageable grid is a sophisticated grid that automatically manages, adapts, monitors, diagnoses and fixes itself. A manageable system has intelligent control embedded into its infrastructure to automate its management procedure. A variety of technologies are available to support grid manageability at both the hardware and software levels. At the software level, a wide range of techniques, from traditional log files to recent technologies such as Java Management Extensions (JMX, http://java.sun.com/ javase/technologies/core/mntr-mgmt/javamanagement) and knowledge technologies, ${ }^{28}$ can support manageability. At the hardware level, technologies from simple embedded sensors ${ }^{29}$ to standalone intelligent robots can achieve this. Additionally, changing the underlying grid architecture-for example, from centralized client/server to $\mathrm{P}^{2} \mathrm{P}^{6}$ structures-can support manageability.

Manageable grids offer a simplified installation and greatly reduce configuration and administration, which, in turn, reduces management costs and dramatically enhances scalability. Existing research in this area includes autonomic grids, ${ }^{30}$ knowledge grids,$^{10}$ and organic grids ${ }^{6}$ (see table 1 ). Hybrid grids use different combinations of management schemes. For instance, a grid environment might implement a distributed P2P management scheme at the cluster level and a centralized management structure at the higher grid level.

Autonomic grids. Autonomic computing, ${ }^{31}$ initiated by IBM in 2001, is named after the human body's autonomic nervous system. The autonomic nervous system regulates body systems without any external help; likewise, an autonomic computing system controls the functioning of computer systems without user intervention. The main goal of autonomic computing is to make managing large computing systems (such as grids) less complex. ${ }^{32}$ 
An autonomic grid can configure, reconfigure, protect, and heal itself under varying and unpredictable conditions and optimize its work to maximize resource use. You can find applications, challenges, and various methods that have been proposed to work toward autonomic grids elsewhere. ${ }^{8}$ Examples of autonomic grid projects include the IBM OptimalGrid ${ }^{7}$ and AutoMAGI. ${ }^{8}$

Knowledge grids. A knowledge grid is an extension to the current grid in which data, resources, and services have well-defined meanings that are annotated with semantic metadata so both machines and humans can understand them. The aim is to move the grid from an infrastructure for computation and data management to a pervasive knowledge-management infrastructure. Examples of knowledge grid projects include OntoGrid (www.ontogrid.net/ontogrid/index.jsp), InteliGrid (www.inteligrid.com), and K-Wf Grid (www.kwfgrid.eu). Several communities are working to realize knowledge grids, including the Semantic Grid Group (www.ogf.org/gf/group_info/view.php?group=sem-rg) from the Open Grid Forum (www.ogf.org). Reviews of the status and future vision of knowledge grids, including applications, challenges, and critical issues, are detailed elsewhere. ${ }^{33,34}$

Organic grids. Traditionally, "organic" means forming an integral element of a whole, having systematic coordination of parts, and/or having the characteristics of an organism and developing in the manner of a living plant or animal. ${ }^{35}$ In grid computing, the organic grid refers to a new design for desktop grids that relies on a decentralized P2P approach, a distributed scheduling scheme, and mobile agents. The basic idea comes from the manner in which complex patterns can emerge from the interplay of many agents in an ant colony. ${ }^{9}$ However, work on organic grids is at a very early stage.

o make the NGG a reality, researchers must address some critical aspects and serious challenges, such as infrastructure agnostic grid middleware, dynamic service composition, user-centricity, dependability, security, and scalability. Some open ethical and philosophical concerns are striking as well. Although grid technologies never had an explicit goal of changing our society, it's likely that emerging grids will have long-term consequences and ethical values (such as those relating to security and privacy) that are much more influential than the Internet.

Additionally, it's not yet clear how these grids will actually be put into practice. As John Thackara put it, "Our dilemma is this: we do not know what needs these new technologies are supposed to meet. In fact, we don't even think about that question, the why. ${ }^{\prime \prime 6}$ Finally, it's important to consider that successful innovation is the result of a specific socioeconomic and technological constellation-the right product, in the right market, at the right time where specific requirements in terms of user needs, pricing, and standards, among others, must be met. ${ }^{37}$

Most emerging grids are still in their infancy. We've indicated the necessity for more research in this domain to establish a solid background and enable the implementation of these promising environments.

\section{References}

1. I. Foster and C. Kesselman, eds., The Grid: Blueprint for a Future Computing Infrastructure, Morgan Kaufmann, 1999.

2. Next Generation Grid(s): European Grid Research 2005-2010, Expert Group Report, 2003, $\mathrm{ftp}: / / \mathrm{ftp}$. cordis.lu/pub/ist/docs/ngg_eg_final.pdf.

3. Future for European Grids: GRIDs and Service Oriented Knowledge Utility, Next Generation GRIDs Expert Group Report 3, 2006, ftp://ftp.cordis.europa.eu/pub/ist/docs/grids/ngg3_eg_final.pdf.

4. K.G. Jeffery, "Next Generation Grids for Environmental Science," Environmental Modelling \& Software, vol. 22, no. 3, 2007, pp.281-287.

5. Next Generation Grids 2: Requirements and Options for European Grids Research 2005-2010 and Beyond, Expert Group Report, 2004, www.semanticgrid.org/docs/ngg2_eg_final.pdf.

6. A.J. Chakravarti, G. Baumgartner, and M. Lauria, "Self-Organizing Scheduling on the Organic Grid," Int'l J. High Performance Computing Applications, vol. 20, no. 1, 2006, pp. 115-130. 
7. T.J. Lehman and J.H. Kaufman, "OptimalGrid: Middleware for Automatic Deployment of Distributed FEM Problems on an Internet-Based Computing Grid," Proc. IEEE Int'l Conf. Cluster Computing, IEEE Press, 2003, pp. 164-171.

8. A. Sajjad et al., "AutoMAGI-An Autonomic Middleware for Enabling Mobile Access to Grid Infrastructure," Proc. Joint Int'l Conf. Autonomic and Autonomous Systems and Int'l Conf. Networking and Services (ICAS-ICNS 2005), IEEE CS Press, 2005, pp. 73-79.

9. A.J. Chakravarti, G. Baumgartner, and M. Lauria, "The Organic Grid: Self-Organizing Computation on a Peer-to-Peer Network," IEEE Trans. Systems, Man, and Cybernetics Part A: Systems and Humans, vol. 35, no. 3, 2005, pp. 373-384.

10. I. Foster and C. Kesselman, eds., The Grid2: Blueprint for a New Computing Infrastructure, Morgan Kaufmann, 2003.

11. K. Amin, G. Laszewski, and A. Mikler, "Toward an Architecture for Ad Hoc Grids," Proc. 12th Int'l Conf. Advanced Computing and Communications (ADCOM 04), 2004, wwwunix.mcs.anl.gov/ laszewsk/papers/vonLaszewski-adhoc-adcom2004.pdf.

12. T. Friese, M. Smith, and B. Freisleben, "Hot Service Deployment in an Ad Hoc Grid Environment," Proc. 2nd Int'l Conf. Service Oriented Computing (ICSOC 04), ACM Press, 2004, pp. 75-83.

13. D. C. Marinescu et al., "Ad Hoc Grids: Communication and Computing in a Power Constrained Environment," Proc. 22nd IEEE Int'l Performance, Computing, and Communications Conf., IEEE Press, 2003, pp. 113-122.

14. S. Shivle et al., "Static Allocation of Resources to Communicating Subtasks in a Heterogeneous Ad Hoc Grid Environment," J. Parallel and Distributed Computing, vol. 66, no. 4, 2006, pp. 600-611.

15. L.W. McKnight, J. Howison, and S. Bradner, "Wireless Grids: Distributed Resource Sharing by Mobile, Nomadic, and Fixed Devices," IEEE Internet Computing, vol. 8, no. 4, 2004, pp. 24-31.

16. S. H. Srinivasan, "Pervasive Wireless Grid Architecture," Proc. 2nd Ann. Conf. Wireless on-Demand Network Systems and Services, IEEE CS Press, 2005, pp. 83-88.

17. J. Hwang and P. Aravamudham, "Middleware Services for P2P Computing in Wireless Grid Networks," IEEE Internet Computing, vol. 8, no. 4, 2004, pp. 40-46.

18. T. Phan, L. Huang, and C. Dulan, "Challenge: Integrating Mobile Wireless Devices into the Computational Grid," Proc. 8th ACM Ann. Int'l Conf. Mobile Computing and Networking, ACM Press, 2002, pp. 271-278.

19. K. Ohta et al., "Design and Implementation of Mobile Grid Middleware for Handsets," Proc. 11th Int'l Conf. Parallel and Distributed Systems (ICPADS 05), IEEE CS Press, 2005, pp. 679-683.

20. A. Sajjad et al., "A Component-Based Architecture for an Autonomic Middleware Enabling Mobile Access to Grid Infrastructure," Proc. Embedded and Ubiquitous Computing Workshops (EUC 2005), LNCS 3823, Springer, 2005, pp. 1225-1234.

21. Bhagyavati and S. Kurkovsky, "Emerging Issues in Wireless Computational Grids for Mobile Devices," Proc. 8th World Multiconf. Systemics, Cybernetics, and Informatics (SCI-2004), 2004, www.cs.ccsu.edu/ stan/research/Grid/Pubs/SCI2004.pdf.

22. L. d.S. Lima et al., "Peer-to-Peer Resource Discovery in Mobile Grids," Proc. 3rd Int'l Workshop Middleware for Grid Computing (MGC 05), ACM Press, 2005, pp. 1-6.

23. S. Kurkovsky, Bhagyavati, and A. Ray, "Modeling a Grid-Based Problem-Solving Environment for Mobile Devices," J. Digital Information Management, vol. 2, no. 2, 2004, pp. 109-114.

24. D.C. Chu and M. Humphrey, "Mobile OGSI.NET: Grid Computing on Mobile Devices," Proc. 5th IEEE/ACM Int'l Workshop Grid Computing, IEEE CS Press, 2004, pp. 182-191.

25. V. Talwar, S. Basu, and R. Kumar, "Architecture and Environment for Enabling Interactive Grids," J. Grid Computing, vol. 1, no. 3, 2003, pp. 231-250.

26. H. Xiao et al., "An Implementation of Interactive Jobs Submission for Grid Computing Portals," Proc. Australasian Workshop Grid Computing and e-Research (AusGrid2005), Australian Computer Soc., 2005, pp. 67-70.

27. J. Han and D. Park, "A Lightweight Personal Grid using a Supernode Network," Proc. 3rd Int'l Conf. Peer-to-Peer Computing (P2P 2003), IEEE CS Press, 2003, pp. 168-175.

28. J. Nichols, H. Demirkan, and M. Goul, "Autonomic Workflow Execution in the Grid," IEEE Trans. Systems, Man and Cybernetics, Part C (Applications and Reviews), vol. 36, no. 3, 2006, pp. 353364.

29. "OGSI-Based System Management: Manageability Services for Linux," white paper, IBM, Aug. 2003, http://whitepapers.silicon.com/0,39024759,60109062p,00.htm.

30. J. Joseph and C. Fellenstein, Grid Computing, IBM Press, 2004.

31. J.O. Kephart and D.M. Chess, "The Vision of Autonomic Computing," Computer, vol. 36, no. 1, 2003, pp. 41-50. 
32. M. Li and M. Baker, The Grid: Core Technologies, Wiley, 2005, pp. 452.

33. D. Roure, N.R. Jennings, and N.R. Shadbolt, "The Semantic Grid: Past, Present, and Future," Proc. IEEE, vol. 93, no. 3, 2004, pp. 669-681.

34. M. Geldof, "The Semantic Grid: Will Semantic Web and Grid Go Hand in Hand?" European Commission, DG Information Soc., 2004, www.semanticgrid.org/documents/Semantic\%20Grid\%20report\%20public.pdf.

35. E. Tofslie, "Organic Grid Design," BFA thesis, College of Letters, Arts, and Social Sciences, Univ. of Idaho, 2002, www.tofslie.com/organicgrid.pdf.

36. J. Thackara, "The Design Challenge of Pervasive Computing," Interactions, vol. 8, no. 3, 2001, pp. 46-52.

37. I. Miles, K. Flanagan, and D. Cox, "Ubiquitous Computing: Toward Understanding European Strengths and Weaknesses," European Science and Technology Observatory Report, PREST, 2002.

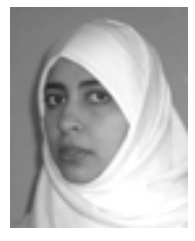

Heba Kurdi is a PhD student in the School of Engineering and Design at Brunel University. Her research interests include personal mobile grids; resource management systems for computational grids; and bee colony optimization and its application in resource scheduling in grid systems. She received her master's degree in applied computer science from King Saud University in Riyadh. Contact her at the Wireless Networks \& Communications Group, School of Eng. and Design, Brunel Univ., Uxbridge, Middlesex UB8 3PH, UK; heba.kurdi@brunel.ac.uk.

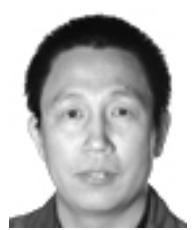

Maozhen Li is a lecturer in the School of Engineering and Design at Brunel University. He received his PhD in 1997 from the Institute of Software, Chinese Academy of Sciences, Beijing. His research interests include grid computing, distributed problemsolving environments for large-scale simulations, intelligent systems, service-oriented computing, and the Semantic Web. He co-authored The Grid: Core Technologies (Wiley, 2005). He has served as a TPC member for grid computing conferences including IEEE CCGrid 05-08, IEEE SKG05-07, and IEEE CSE 08. He's on the editorial boards of Encyclopedia of Grid Computing Technologies and Applications and the International Journal of Grid and High Performance Computing. He's a member of the IEEE. Contact him at the School of Eng. and Design, Brunel Univ., Uxbridge, Middlesex UB8 3PH, UK; maozhen.li@brunel.ac.uk.

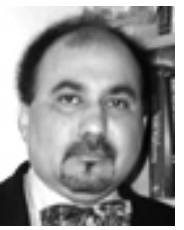

Hamed Al-Raweshidy is a research professor and the head of the Wireless Networks \& Communications Research Group in the School of Engineering and Design at Brunel University. His research interests include network optimization, mesh and ad hoc networks, radio over fiber, PAN and PN, and IP mobility. He received his PhD for work in spread spectrum multiplexing for communication networks. He holds a number of projects with EPSRC and EU. He's a senior member of the IEEE, an IEE fellow, and a member of New York Academy of Sciences. Contact him at the Wireless Networks \& Communications Group, School of Eng. and Design, Brunel Univ., Uxbridge, Middlesex UB8 3PH, UK; hamed.alraweshidy@brunel.ac.uk.

\section{Cite this article:}

Heba Kurdi, Maozhen Li, and Hamed Al-Raweshidy, "A Classification of Emerging and Traditional Grid Systems," IEEE Distributed Systems Online, vol. 9, no. 3, 2008, art. no. 0803-03001. 